\title{
Importancia de la rendición de cuentas y las transferencias de bienes privados en la decisión del voto: el caso del FONDEN en México, 2006-2013
}

\author{
The importance of accountability and private goods transfers \\ in the voting decision: the case of FONDEN in Mexico, 2006-13
}

\author{
BRISNA BELTRÁN \\ El Colegio de México, México
}

\section{Como citar/Citation}

Beltrán, B. (2018). Importancia de la rendición de cuentas y las transferencias de bienes privados en la decisión del voto: el caso del FONDEN en México, 2006-2013. Revista Española de Ciencia Política, 47, 13-38.

Doi:https://doi.org/10.21308/recp.47.01

\section{Resumen}

Usualmente se argumenta que las medidas cortoplacistas, como la entrega de transferencias o la disminución de impuestos, pueden ser recompensadas electoralmente, lo que facilita la reelección del partido en el poder. El objetivo de este artículo es determinar si las transferencias gubernamentales de bienes privados son realmente suficientes para influir en el proceso de decisión del voto. Para ello, se emplea información de todas las transferencias realizadas por el Fondo de Desastres Naturales (FONDEN) en cada declaración de emergencia en México entre 2006 y 2013. Los resultados muestran que el apoyo electoral en los municipios afectados por un fenómeno natural es entre 0,3 y 4,9 puntos porcentuales menor que en los municipios no afectados. Sin embargo, si la magnitud de la emergencia es tal que precisa la entrega de bienes privados para garantizar el bienestar de la población, la penalización electoral puede llegar a ser de 8,8 puntos porcentuales. La conclusión es que los votantes no actúan con miopía electoral, pues al decidir su voto no solo consideran los recursos recibidos. Las declaraciones de emergencia son un mecanismo de rendición de cuentas, y son interpretadas por los votantes como una señal de un mal desempeño del gobernante.

Palabras clave: comportamiento electoral, voto retrospectivo, voto retrospectivo económico, miopía electoral, FONDEN, México, desastres naturales.

\begin{abstract}
It is usually argued that short-term measures such as the delivery of transfers of tax reductions may be electorally rewarded, thus increasing the ruling party's chances of being re-elected. The
\end{abstract}


objective of this article is to determine whether governmental transfers of private goods are really sufficient to influence the voting decision process. To do so, I use data about all the transfers made by FONDEN in each emergency declaration in Mexico between 2006 and 2013. The results show that electoral support in affected municipalities is between 0.3 and 4.9 percentage points lower than in unaffected municipalities. However, if the magnitude of the emergency is such that it requires the delivery of private goods to guarantee the population wellbeing, the electoral penalty may reach up to 8.8 percentage points. The conclusion is that voters are not short-sighted for, when deciding their vote, voters do not only consider the resources they have received. Emergency Declarations are accountability mechanisms, and they are interpreted by the voters as a signal of the governor's bad performance.

Keywords: electoral behavior, retrospective vote, retrospective pocketbook, electoral shortsightedness, FONDEN, Mexico, natural disasters.

\section{INTRODUCCIÓN}

Las elecciones en los sistemas democráticos permiten reemplazar a los gobernantes con poca capacidad o mal desempeńo. No obstante, recolectar y procesar la cantidad de información necesaria para realizar un voto informado puede ser un proceso muy costoso. En este trabajo se estudia si los electores son fácilmente influenciables por las transferencias privadas o si incorporan otra información en su proceso de decisión del voto.

De acuerdo con la teoría del voto retrospectivo (TVR), los resultados de las políticas públicas y el bienestar económico son utilizados por los votantes para evaluar el desempeño del partido gobernante y decidir si apoyar o no su reelección (Fiorina, 1981). Este esquema brinda incentivos para que el gobernante actúe tácticamente y adopte políticas que beneficien a los electores y les motiven a brindarles su apoyo electoral (Cox y McCubbins, 1986; Lindbeck y Weibull, 1987; Persson y Tabellini, 2000). En términos de Healy y Lenz (2014), los electores sustituyen las consecuencias de todo el desempeño del gobernante por las condiciones que imperan al final de un proceso electoral. No obstante, es posible que el electorado adquiera consciencia de esta estrategia y evite ser manipulado (Bonfiglioli y Gancia, 2013).

En contraposición, la teoría del voto prospectivo (TVP) sostiene que los votantes examinan las promesas de campaña y eligen al candidato cuyo posicionamiento sea más cercano al suyo y le ofrezca una mayor utilidad esperada (Downs 1957). Consecuentemente, el voto no promueve una rendición de cuentas. La posibilidad de reelección depende solo de las promesas del gobernante y de su opositor. En este contexto, las ofertas políticas pueden ser equiparables con la adquisición de servicios que serán realizados en el futuro (Nielsen y Larsen 2014: 154).

Usualmente, se argumenta que los electores son miopes y deciden su voto solo con base en la situación económica, general o personal que impera en el momento de tomar su decisión, ignorando la información previa. Los estudios empíricos a favor de la TVR suelen utilizar información acerca de la reacción electoral a ciertas políticas 
o a la transferencia de recursos gubernamentales (De Mesquita y Friedenberg, 2006; Pop-Eleches y Pop-Eleches, 2009; Elinder et al., 2015).

Gran parte de los estudios empíricos respecto a este tema en países en vías de desarrollo suelen analizar el impacto electoral de los programas de transferencias condicionadas (PTC). No obstante, este tipo de información presenta algunas limitantes. En primer lugar, las conclusiones obtenidas carecen de validez externa, pues los PTC se suelen entregar a personas con características específicas que no son observables en toda la población, como estar en condición de pobreza. En segundo lugar, y más importante aún, en la mayoría de estos estudios no se descarta que los beneficiarios no sean seleccionados con criterios electorales, como niveles de votación en una zona, por lo que es posible que los resultados obtenidos tengan un sesgo implícito.

En este trabajo se utiliza información acerca del Fondo de Desastres Naturales (FONDEN) para la Atención de Emergencias en México, para explorar si los ciudadanos incorporan la recepción de transferencias gubernamentales en su proceso de toma de decisión del voto. El FONDEN es un instrumento financiero interinstitucional del Gobierno mexicano que, mediante una declaración de emergencia (DE), brinda recursos a gobiernos subnacionales con el fin de mitigar los efectos perturbadores de fenómenos naturales (SEGOB, 2010: art. 1). Dado que los fenómenos naturales se producen aleatoriamente, las DE y las transferencias realizadas por el FONDEN tienen esta misma característica. Por lo tanto, los datos estudiados son tan buenos como si hubieran sido generados experimentalmente.

A pesar de que los recursos transferidos por el FONDEN pueden llegar a equiparar el presupuesto anual de un municipio, las consecuencias de las DE y las transferencias realizadas por el FONDEN no han sido exploradas. Este es el primer trabajo en el que se estudian las implicaciones de las DE y las transferencias realizadas. Si los votantes son retrospectivos, pueden interpretar la existencia de una DE, o de las transferencias, como una señal de la capacidad y el desempeño del gobernante, por lo que debería observarse alguna incidencia sobre los resultados electorales. En contraste, si los votantes son prospectivos, no debería observarse ninguna consecuencia de la existencia de una DE o sus transferencias.

Este trabajo contribuye a la literatura en tres vertientes. Por una parte, utilizando información novedosa, se presenta evidencia que apoya la TVR y que, además, sugiere que los votantes no son cortoplacistas, como usualmente se argumenta, sino que incorporan información adicional. En segundo lugar, las características de la información permiten proveer estimaciones libres de sesgos implícitos atribuibles a los intereses políticos con los que se pueden repartir otros recursos. Finalmente, a diferencia de otros estudios que carecen de validez externa, pues solo hacen referencia a una población específica, los resultados de esta investigación sí son generalizables pues se emplean datos de población con diversas características socioeconómicas.

Este artículo se divide en cinco secciones, además de la presente. En la siguiente sección se discuten algunos trabajos sobre la influencia de las transferencias gubernamentales en las evaluaciones retrospectivas que hacen los votantes. La tercera sección explica brevemente que es el FONDEN. La cuarta sección presenta las fuentes, los 
datos y la estrategia empírica que se utilizan en este trabajo. En la quinta sección se discuten los resultados. La última sección está dedicada a conclusiones.

\section{TRANSFERENCIAS GUBERNAMENTALES Y VOTO RETROSPECTIVO}

De acuerdo con la TVR, obtener toda la información necesaria para evaluar el desempeño de un gobernante es muy costoso y prácticamente imposible para los ciudadanos. Debido a ello, los votantes emplean su propio bienestar económico para evaluar el desempeño del gobernante (Fiorina, 1981). Por lo tanto, la probabilidad de que un gobernante (o su partido) sea reelegido será mayor si los votantes consideran que su situación económica es buena (Hellwig, 2010; Lewis-Beck y Stegmaier, 2007; Labonne, 2013).

La evaluación retrospectiva del desempeño del gobernante no implica que los votantes analicen todo el período gubernamental. De hecho, la evidencia empírica sugiere que los votantes actúan con miopía electoral y solo se centran en los últimos seis o doce meses (Achen y Bartels, 2004; Lenz, 2011; Healy y Lenz, 2014). Dado que los votantes tratan de elegir a los mejores candidatos, los gobernantes tienen incentivos para implementar políticas que beneficien a sus electores, como las políticas de control de precios, transferencias, subsidios o exenciones fiscales (Rogoff, 1990; Brender y Drazen, 2005; Shia y Svensson, 2006; Drazen y Eslava, 2010), aunque dichas políticas sean perjudiciales a largo plazo (Ladd, 2010: 3). Independientemente de la forma que adopten, la TVR sostiene que si los votantes consideran que su situación económica es mejor, premiarán al gobernante.

Una manera frecuente de estudiar el impacto electoral del gasto gubernamental en los países en desarrollo es a través de los PTC para combatir la pobreza, como el programa Progresa-Oportunidades-Prospera (POP) en México o el programa Bolsa Familia $(\mathrm{BF})$ en Brasil. La entrega de beneficios privados, principalmente a las personas en condición de pobreza, tiene una incidencia directa sobre su bienestar económico, por lo que, de acuerdo con la TVR, este cambio debería implicar un mayor apoyo electoral al partido en el Gobierno.

La evidencia empírica sugiere que los beneficiarios de los PTC sí recompensan electoralmente al gobernante por las transferencias. Baez (2012), por ejemplo, concluye que los beneficiarios del programa Familias en Acción (FA) en Colombia tienen una probabilidad de votarle entre 1,6 y 2,5 puntos porcentuales más, y su apoyo al gobernante es entre el 1,6 y el 1,8 \% superior. En el mismo sentido, Zucco (2013) encuentra que los recursos entregados por el $\mathrm{BF}$ incrementan hasta un $45 \%$ la probabilidad de votar a favor del gobernante. Por su parte, Manacorda et al. (2011) sostienen que los beneficiarios del Plan de Atención Nacional a la Emergencia Social (PANES) en Uruguay son entre 11 y 13 puntos porcentuales más propensos a apoyar al partido en el poder, y que el efecto de las transferencias puede durar hasta un año después de que se efectuaron.

Para el caso de México, Rodríguez-Chamussy (2009) concluye que entre 1997 y 2007 las transferencias del POP representaron en promedio 2,8 puntos porcentuales más de votos para el partido gobernante en el municipio. En tanto que, Díaz-Cayeros 
et al.(2009) hallan que los beneficiarios fueron un $11 \%$ más propensos a votar por el partido gobernante a nivel nacional que los no beneficiarios durante las elecciones presidenciales de 2006. Por otro lado, De la O (2013) sostiene que las transferencias del POP aumentan hasta $7 \%$ la participación electoral y 3,7 puntos porcentuales la votación a favor del partido gobernante.

Por otra parte, también se ha encontrado que un buen desempeño del gobernante puede ser ocultado por sucesos negativos. De hecho, algunos autores sugieren que los votantes incluso pueden castigar al gobernante por fenómenos fuera de su control, como el aumento de ataques de tiburones o las lluvias monzónicas (Achen y Bartels, 2012; Cole et al., 2012). La penalización por acontecimientos no atribuibles al desempeńo del gobernante podría ser interpretada como un acto irracional de los votantes. Sin embargo, de acuerdo con Ashworth y de Mesquita (2013), estos sucesos también brindan información acerca del desempeño del gobernante. Por ejemplo, el aparente voto de castigo que se observa tras la ocurrencia de un desastre natural, en realidad puede estar capturando la evaluación de la respuesta gubernamental a los choques externos o de la implementación de medidas preventivas.

El planteamiento de Ashworth y de Mesquita (2013) es persuasivo, pues sugiere que los individuos no solo se concentran en su bienestar inmediato, sino que también incluyen las acciones gubernamentales en su proceso de toma de decisión. En este contexto, Chen y Healy (2015) estudian el impacto electoral de la ayuda entregada por FEMA en Florida después de la ocurrencia de cuatro huracanes en 2004. Concluyen que, mientras los damnificados son altamente sensibles a las transferencias gubernamentales, quienes reciben recursos sin haber sido dañados severamente, no recompensan al gobernante.

Para contribuir a la literatura, en este trabajo se explora la importancia relativa de la ocurrencia de las DE y las transferencias de bienes privados hechas tras ellas en el proceso de toma de decisión de los votantes. Una DE puede ser interpretada por los votantes como una señal negativa respecto al grado de vulnerabilidad en el que se encuentran y culpabilizar de ello a su gobernante. No obstante, también es posible que las transferencias gubernamentales ayuden a soslayar dicha responsabilidad e incluso a obtener una recompensa electoral.

Es posible que las diferentes conclusiones en la literatura se deban a las características de la información analizada. En esta investigación se emplea información de todas las DE realizadas por el FONDEN entre 2006 y 2013. El uso de información referente a las transferencias realizadas después de que un fenómeno natural afecte a la población tiene varias ventajas. Las transferencias del FONDEN permiten identificar los cambios en el comportamiento electoral debido a transferencias únicas y extraordinarias, y sobre las cuales los receptores no tienen titularidad, como las que suceden en un contexto de patronazgo electoral. En contraste, los PTC implican transferencias continuas y periódicas, de tal forma que el mayor apoyo electoral puede deberse a la transferencia per se o bien al miedo de que desaparezca ante un cambio de Gobierno.

Por otra parte, al emplear información sobre las transferencias realizadas después de la ocurrencia de un fenómeno natural, se evitan los sesgos inducidos por la selección 
de beneficiarios que está presente en casi todos los estudios que emplean información sobre PTC. En la mayoría de dichas investigaciones se asume que, como los recursos de los PTC son entregados de acuerdo con criterios objetivos (como tener ingresos por debajo de un umbral), no existe una relación clientelar. No obstante, los intereses electorales pueden estar presentes en otras formas. De la O (2013), por ejemplo, encuentra que las primeras comunidades atendidas por el POP tenían, antes de su implementación, una participación electoral de 5 puntos pocentuales superior y una votación de 3,7 puntos porcentuales mayor por el partido que gobernaba respecto de los municipios atendidos en etapas posteriores. Dado que el uso de información sobre los PTC no descarta que los beneficiarios fueran seleccionados ex ante de acuerdo con criterios electorales, todos los resultados obtenidos presentan un sesgo por variable omitida que sesga los resultados.

Aunado a esto, las conclusiones obtenidas empleando información sobre los PTC carecen de validez externa, pues solo proporcionan evidencia del efecto de las transferencias sobre una población que tiene características específicas (como encontrarse en situación de pobreza). Dado que las conclusiones no provienen de una población aleatoria, se desconoce cómo reaccionan las personas con características distintas. En contraste, al utilizar los desastres naturales como estrategia de identificación se tiene validez externa, pues su ocurrencia afecta a personas con distintas características sociales.

\section{FONDO DE DESASTRES NATURALES, FONDEN}

El FONDEN fue creado en 1996 como parte de la línea presupuestaria federal Ramo 23, para asegurar el financiamiento de las actividades postdesastre. Es un instrumento financiero interinstitucional que brinda recursos a gobiernos subnacionales con el fin de mitigar los efectos perturbadores de fenómenos naturales (SEGOB, 2010: art. 1). Antes de su creación, no existía ningún mecanismo a través del cual se pudieran proporcionar fondos extraordinarios para los procesos de restauración, reconstrucción y recuperación, por lo que atender tales necesidades implicaba el desvío presupuestario de otras áreas y actividades.

Cuando un fenómeno natural pone en riesgo o daña a la población, se publica una $\mathrm{DE}$, la cual garantiza el acceso a recursos para proveer bienes privados ${ }^{1}$. Una DE puede solicitarse antes de que un fenómeno natural tenga consecuencias perturbadoras. Basta con que exista «la inminencia, alta probabilidad o presencia de una situación anormal generada por un fenómeno natural perturbador, que puede propiciar un riesgo exce-

1. Los bienes entregados por el FONDEN son privados, aun si son financiados con recursos públicos. La definición del tipo de bien se realizada con base en su uso, no su financiamiento. Por definición un bien es privado si cumple con dos características: es rival y excluyente. La rivalidad significa que el consumo por una persona impide que sea consumido por otra. La exclusión implica que es posible negar el consumo a usuarios potenciales. Un trabajo dentro de la estructura gubernamental es un ejemplo perfecto de un bien privado proporcionado por el Gobierno. 
sivo» (SEGOB 2012: art. 8). Es decir, las DE pueden tener un carácter preventivo, no solo correctivo. Los recursos solo son transferidos a las entidades federativas y municipios si el fenómeno natural afecta el bienestar de la población ${ }^{2}$.

Entre 2006 y 2013, 1475 municipios en México tuvieron 4605 DE³. El 79,8 \% de los municipios tuvieron como máximo tres declaraciones durante ese período. El $30,9 \%$ de las DE no recibió recursos, mientras que el 69,1\% recibieron al menos una transferencia (tabla 1).

TABLA I.

DeClaraciones de EMERGENCIA, DE ACUERdo CON LA RECEPCión DE RECURSOS DEL FONDEN, 2006-2013

\begin{tabular}{lcc}
\hline Recibió recursos del FONDEN & Número & $\%$ \\
\hline No & 1.425 & 30,9 \\
\hline Sí & 3.180 & 69,1 \\
\hline Total & 4.605 & 100,0 \\
\hline
\end{tabular}

Fuente: elaboración propia con información del CENAPRED (2013).

Es importante resaltar que la distribución de las DE por grado de marginación es muy similar a la proporción de municipios que existen en cada categoría del grado de marginación (tabla 2). Esto sugiere que, al igual que los fenómenos naturales, las DE ocurren de manera aleatoria, lo que descarta la existencia de sesgos en la decisión de promover una DE y transferir recursos.

TABLA 2.

TOTAL DE MUNICIPIOS POR GRADO DE MARGINACIÓN, 2000-2OI3

\begin{tabular}{lcc}
\hline Grado de Marginación & Municipios $\%$ & $\%$ \\
\hline Muy Bajo & 10,7 & 10,2 \\
\hline Bajo & 16,9 & 16,1 \\
\hline Medio & 25,4 & 25,7 \\
\hline Alto & 30,9 & 29,8 \\
\hline Muy Alto & 16,1 & 18,2 \\
\hline Total & 100,0 & 100,0 \\
\hline
\end{tabular}

Fuente: elaboración propia con información del CONAPO (2013). El coeficiente de correlación de Pearson revela una fuerte relación entre la distribución de municipios por grado de marginación y la ocurrencia de Emergencias $(\operatorname{Pr}=0,978)$.

2. Los recursos transferidos son en especie y solo contemplan bienes privados.

3. Se excluyen 450 declaraciones de emergencia ocurridas en municipios gobernados por Usos y Costumbres debido a que no proporcionan información sobre los resultados electorales o del partido de gobierno municipal. 
Una posible preocupación es que las variables políticas determinen las DE o la entrega de recursos. En particular, preocupa que los municipios con gobierno yuxtapuesto, es decir aquellos gobernados por partidos distintos al que rige en el nivel estatal, tengan un menor acceso a recursos que los municipios con gobiernos alineados. No obstante, los datos sugieren que la existencia de un gobierno yuxtapuesto no causa ningún sesgo político en las DE (tabla 3). Los municipios con gobiernos yuxtapuestos o alineados reciben recursos con frecuencia similar. Si hubiera un sesgo partidista, debería haber una diferencia en esta.

TABLA 3.

Municipios que recibieron recursos del FONDEN tras una Declaración de EmerGENCIA, POR GOBIERNO YUXTAPUESTO, 2006-20I3

\begin{tabular}{lrrr}
\hline \multirow{2}{*}{ Gobierno yuxtapuesto } & \multicolumn{2}{c}{ Recibió recursos del FONDEN } & \multirow{2}{*}{ Total } \\
\cline { 2 - 3 } & \multicolumn{1}{c}{ No } & \multicolumn{1}{c}{ Sí } & \\
\hline \multirow{2}{*}{ No } & 576 & 1.442 & 2.018 \\
& $28,5 \%$ & $71,5 \%$ & $100,0 \%$ \\
\hline \multirow{2}{*}{ Sí } & 849 & 1.738 & 2.587 \\
& $32,8 \%$ & $67,2 \%$ & $100,0 \%$ \\
\multirow{2}{*}{ Total } & 1.425 & 3.180 & 4.605 \\
& $30,9 \%$ & $69,1 \%$ & $100,0 \%$ \\
\hline
\end{tabular}

Fuente: elaboración propia con información de CENAPRED (2013), del CIDAC (2013), y de los institutos electorales estatales. El coeficiente de correlación de Pearson no rechaza la hipótesis de que gobiernos yuxtapuestos y alineados reciben con igual frecuencia recursos tras una $\mathrm{DE}(\operatorname{Pr}=0,395)$.

Por otra parte, la distribución de recursos desagregada por partido político en el gobierno municipal y estatal tampoco sugiere ningún sesgo partidista. De acuerdo con la tabla 4, todos los municipios, independientemente del partido que los gobierne, reciben recursos más del $60 \%$ de las veces.

TABLA 4.

Transferencias del FONDEN POR EMERGENCIA, POR PARTIDO POLÍtico GOBERNANTE EN EL MUNICIPIO, 2006-20I3

\begin{tabular}{lrrr}
\hline \multirow{2}{*}{ Gobierno Municipal } & \multicolumn{2}{c}{ Recibió recursos del FONDEN } & \multirow{2}{*}{ Total } \\
\cline { 2 - 3 } & \multicolumn{1}{c}{ No } & \multicolumn{1}{c}{ Sí } & \\
\hline \multirow{2}{*}{ PAN } & 373 & 957 & 1.330 \\
& $28,0 \%$ & $72,0 \%$ & $100,0 \%$ \\
\hline \multirow{2}{*}{ PRI } & 710 & 1.621 & 2.331 \\
& $30,5 \%$ & $69,5 \%$ & $100,0 \%$ \\
\hline \multirow{2}{*}{ PRD } & 167 & 335 & 502 \\
& $33,3 \%$ & $66,7 \%$ & $100,0 \%$ \\
\hline
\end{tabular}




\begin{tabular}{lccc}
\cline { 2 - 3 } Gobierno Municipal & \multicolumn{2}{c}{} \\
\cline { 2 - 3 } & \multicolumn{2}{c}{ Recibió recursos del FONDEN } & \multirow{2}{*}{ Total } \\
\hline \multirow{2}{*}{ Otro } & No & \multicolumn{1}{c}{ Sí } & 442 \\
& 175 & 267 & $100,0 \%$ \\
\hline \multirow{2}{*}{ Total } & $39,6 \%$ & $60,4 \%$ & 4.605 \\
& 1.425 & 3.180 & $100,0 \%$ \\
\hline
\end{tabular}

Fuente: elaboración propia con información del CENAPRED (2013), del CIDAC (2013), y de los institutos electorales estatales. La distribución de recursos por partido político fue verificada con pruebas de correlación de Pearson. Ningún partido parece recibir recursos con una frecuencia distinta a otros partidos políticos.

\section{METODOLOGÍA}

Se emplea una metodología cuasi-experimental utilizando datos del FONDEN para la Atención de Emergencia. La estrategia econométrica requiere identificar cómo varía el comportamiento electoral entre tres diferentes tipos de municipios: (1) los que tuvieron una DE y recibieron recursos del FONDEN; (2) los que tuvieron una DE preventiva, pero no recibieron recursos del FONDEN; y (3) los que no tuvieron ningún tipo de Declaratoria. Se emplean todas las DE ocurridas durante el período 20062013, por fenómenos hidrometeorológicos, ${ }^{4}$ que son los más comunes. ${ }^{5}$

\section{Fuentes de información}

Debido a que no existe información sistematizada respecto a las DE y los recursos transferidos en cada una, se utilizan distintas fuentes de datos. El presente es uno de los primeros trabajos en los que se explora cómo las transferencias realizadas tras una $\mathrm{DE}$ influyen en el comportamiento electoral en México, y el primero que analiza las consecuencias electorales del FONDEN.

La información sobre las DE proviene del Centro Nacional de Prevención de Desastres (CENAPRED, 2013), que provee información acerca de todas las DE, su fecha y lugar de ocurrencia, y el fenómeno natural que las ocasionó. La información respecto de las transferencias en especie realizadas en cada DE fue obtenida del Sistema Nacional de Protección Civil (SINAPROC, 2014). El valor de mercado de estos productos se calculó utilizando datos de precios del Instituto Nacional de Estadística y Geografía (INEGI, 2013a) y de la Secretaría de Desarrollo Social (SEDESOL). La

4. Incluye eventos meteorológicos como huracanes, ciclones tropicales y tifones; fenómenos hidrológicos causados por desviaciones del ciclo natural del agua; eventos climatológicos como las sequías, y algunos brotes biológicos relacionados principalmente con enfermedades relacionadas con el agua.

5. Otras causas de una DE pueden proceder de eventos geológicos e incendios forestales. 
información electoral se obtuvo de la base de datos electorales CIDAC, elaborada por el Centro de Investigación para el Desarrollo, AC. (CIDAC, 2013), y de los diferentes institutos electorales estatales. Las fechas de las elecciones locales y de las tomas de posesión se obtuvieron del Tribunal Electoral del Poder Judicial de la Federación (TEPJF, 2013). Estas fechas se utilizan para saber qué DE se produjeron antes de cada elección local.

Es importante destacar que los denominados desastres naturales, en realidad son fenómenos socionaturales en los que concurren condiciones sociales y económicas y un fenómeno natural. Debido a esto, es necesario controlar las condiciones socioeconómicas preexistentes a la ocurrencia de una DE. Dado que la vulnerabilidad a los fenómenos naturales puede estar relacionada con la falta de servicios públicos y las carencias sociales, se incluyen la proporción de población con analfabetismo, la proporción de población con primaria incompleta, la proporción de hogares sin drenaje, la proporción de hogares sin energía eléctrica, la proporción de hogares sin agua potable, la proporción de hogares con hacinamiento y la proporción de hogares con piso de tierra. Junto a esto, y para controlar la vulnerabilidad geográfica, se incluyen tres variables continuas que revelan la latitud, longitud y altitud de los municipios en la muestra. Estas variables capturaran si algún municipio, por su ubicación geográfica, es más propenso a experimentar algún fenómeno natural. Tanto la información demográfica como la geográfica provienen del INEGI.

\section{Estadistica descriptiva}

La unidad de observación en este estudio es un municipio en cada período de gobierno municipal de tres años, entre 2000 y 2013, que al finalizar fue seguido de elecciones válidas ${ }^{6}$. En total, la base de datos contiene 4177 observaciones, correspondientes al período 2006-2013: 1172 municipios que tuvieron una DE y recibieron recursos; 1088 municipios que tuvieron una $\mathrm{DE}$ y no recibieron recursos, y 1917 que no tuvieron ningún tipo de declaración durante un trienio.

Un mismo municipio puede aparecer más de una vez en la base de datos. Cada vez hace referencia a un período de gobierno distinto y, en consecuencia, a un titular de gobierno y elecciones municipales diferentes. Cada trienio en el que hubo, al menos, una $\mathrm{DE}$ es clasificado de acuerdo con si recibió o no, por lo menos una vez, recursos del FONDEN. Para evitar problemas de identificación a causa de la existencia de múltiples DE durante un mismo período, los recursos transferidos en cada una de las DE del periodo de gobierno fueron agregadas. Este tratamiento evita la existencia de tratamientos repetidos y los posibles sesgos asociados. En la tabla 5 se presenta la estadística descriptiva de los datos utilizados.

6. Se excluyen de la muestra los municipios gobernados por Usos y Costumbres, los que tuvieron elecciones inválidas o extraordinarias, y aquellos con elecciones en 2013 o posteriores. 
TABLA 5 .

EsTADÍSTICA DESCRIPTIVA

\begin{tabular}{|c|c|c|c|c|c|}
\hline Variable & Obs & Media & Desv. est. & Mín. & Máx. \\
\hline $\begin{array}{l}\text { Voto partido gobernante } \\
\text { municipal }\end{array}$ & 4.177 & 0,3829 & 0,2038 & 0 & 1 \\
\hline Voto partido gobernante estatal & 4.177 & 0,3402 & 0,2162 & 0 & 1 \\
\hline $\begin{array}{l}\text { Municipio no recibió } \\
\text { transferencias del FONDEN }\end{array}$ & 4.177 & 0,7194 & 0,4493 & 0 & 1 \\
\hline $\begin{array}{l}\text { Municipio tuvo Declaración de } \\
\text { Emergencia }\end{array}$ & 4.177 & 0,5411 & 0,4984 & 0 & 1 \\
\hline $\begin{array}{l}\text { Municipio recibió transferencias } \\
\text { del FONDEN }\end{array}$ & 4.177 & 0,2806 & 0,4493 & 0 & 1 \\
\hline $\begin{array}{l}\text { Número de autorizaciones de } \\
\text { recursos }\end{array}$ & 4.177 & 2,4163 & 4,9817 & 0 & 58 \\
\hline $\begin{array}{l}\text { Transferencias FONDEN per } \\
\text { cápita }\end{array}$ & 4.177 & 0,1060 & 0,3036 & 0 & 6,4698 \\
\hline $\begin{array}{l}\text { Municipio no tuvo ninguna } \\
\text { Declaración }\end{array}$ & 4.177 & 0,4589 & 0,4984 & 0 & 1 \\
\hline Gobierno yuxtapuesto & 4.177 & 0,5688 & 0,4953 & 0 & 1 \\
\hline PAN gobierna municipio & 4.177 & 0,2554 & 0,4362 & 0 & 1 \\
\hline PRI gobierna municipio & 4.177 & 0,5449 & 0,4980 & 0 & 1 \\
\hline PRD gobierna municipio & 4.177 & 0,1302 & 0,3366 & 0 & 1 \\
\hline $\begin{array}{l}\text { Un partido distinto gobierna } \\
\text { municipio }\end{array}$ & 4.177 & 0,0632 & 0,2434 & 0 & 1 \\
\hline PAN gobierna Estado & 4.177 & 0,2191 & 0,4137 & 0 & 1 \\
\hline PRI gobierna Estado & 4.177 & 0,5176 & 0,4998 & 0 & 1 \\
\hline PRD gobierna Estado & 4.177 & 0,2092 & 0,4068 & 0 & 1 \\
\hline $\begin{array}{l}\text { PAN gobierna municipio * No } \\
\text { FONDEN }\end{array}$ & 4.177 & 0,1707 & 0,3763 & 0 & 1 \\
\hline $\begin{array}{l}\text { PRD gobierna municipio }{ }^{*} \text { No } \\
\text { FONDEN }\end{array}$ & 4.177 & 0,0970 & 0,2959 & 0 & 1 \\
\hline $\begin{array}{l}\text { PAN gobierna Estado * No } \\
\text { FONDEN }\end{array}$ & 4.177 & 0,1460 & 0,3532 & 0 & 1 \\
\hline $\begin{array}{l}\text { PRD gobierna Estado } * \text { No } \\
\text { FONDEN }\end{array}$ & 4.177 & 0,1717 & 0,3771 & 0 & 1 \\
\hline
\end{tabular}

Fuente: elaboración propia con información del CENAPRED (2013), del CIDAC (2013), de los institutos electorales estatales, y el INEGI (2013b). La información acerca de las transferencias per cápita está en cientos de pesos, a precios constantes de la segunda quincena de diciembre del 2010. 


\section{Estrategia empirica}

La estrategia de identificación se basa en el hecho de que (1) no todos los municipios tuvieron una DE; (2) la ocurrencia de una DE es aleatoria, y (3) que no todos los municipios que tuvieron una emergencia recibieron recursos. Se sostiene que, de no existir ninguna $\mathrm{DE}$, los tres grupos se comportarían de la misma manera.

Los municipios que no tuvieron ninguna $\mathrm{DE}$ sirven como el grupo de control debido a que no recibieron ningún estimulo. Consecuentemente, cualquier diferencia en el comportamiento electoral puede ser atribuida a la clase de tratamiento que recibieron: (1) tener una DE y recibir transferencias, y (2) tener una DE y no recibir ninguna transferencia. Más aún, la estrategia de identificación también permite validar la TVR respecto a la TVP. De no observarse ninguna diferencia entre los comportamientos electorales de los tres grupos, implicaría que los votantes en realidad no son retrospectivos, sino prospectivos, es decir, que no consideran su bienestar para evaluar la idoneidad de un candidato, sino que solo se centran en sus promesas y propuestas. Tal observación brindaría evidencia a favor de la TVP y en contra de la TVR.

Se utiliza un modelo de regresión lineal ordinaria usando los datos agrupados. El modelo general es:

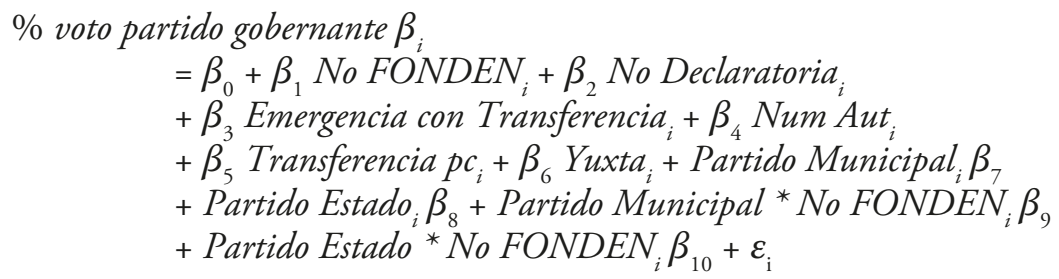

La unidad de observación es el municipio $i$ en el año $t$. La variable dependiente es la proporción de votos que obtiene el partido gobernante municipal en las elecciones locales, y adopta valores entre $[0,1]$. La variable dependiente se especifica de dos maneras diferentes. Primero, se define como la proporción de votos que el partido gobernante en el municipio obtuvo en las elecciones municipales. A continuación, se define como la proporción de votos que el partido que gobierna la entidad federativa obtuvo en las elecciones municipales. En ambos casos, los resultados electorales son de la elección municipal más cercana posterior a la $\mathrm{DE}$.

La variable independiente clave es No FONDEN, la cual es una dicotómica igual $\mathrm{a} « 0 »$ cuando el municipio recibió recursos del FONDEN en una DE y «1» cuando el municipio tuvo una declaratoria, pero no recibió ninguna transferencia. Por lo tanto, $\beta_{1}$ es el efecto sobre la proporción de votos de tener una $\mathrm{DE}$ y no recibir recursos, en relación con quienes sí los recibieron.

La variable No declaratoria es una variable dicotómica, que es igual a «1» cuando el municipio no tuvo ninguna declaración durante el trienio de gobierno, $\mathrm{y}$ «0» en caso contrario. $\mathrm{Si} \beta_{2}>0$ significa que los electores afectados por una emergencia castigan al partido gobernante, y votan menos por él. Por el contrario, si $\beta_{2}<0$ entonces 
significa que los votantes en los municipios que tuvieron una declaratoria y recibieron recursos del FONDEN apoyan más al partido gobernante, posiblemente como consecuencia de las transferencias recibidas.

La variable Emergencia con Transferencia contiene la proporción de DE en el municipio que recibieron recursos del FONDEN durante un trienio. En los casos en que no hubo declaratoria o que nunca recibieron recursos es igual a «0». Por su parte, Num Aut es una variable discreta, que adopta valores de 0 a 41 . Representa el número de veces que el gobernador del estado solicitó y recibió recursos del FONDEN en cada $\mathrm{DE}^{7}$. Cuando los municipios no tuvieron una declaración o no recibieron recursos esta variable es igual a «0».

La variable Transferencia $p c$ representa el monto total de la transferencia per cápita que cada municipio recibió durante una DE. Es igual a «0» cuando el municipio no recibe recursos del FONDEN. La variable se codificó en cientos de pesos. Por lo tanto, $\beta_{5}$ debe interpretarse como la cantidad que la proporción de votos varía por cada cien pesos que las transferencias per cápita del FONDEN aumentan.

Partido Municipal y Partido Estado son vectores de variables dummy, que indican el partido que gobernaba el municipio y la entidad federativa, respectivamente, en cada trienio. El grupo de referencia está compuesto por los municipios y entidades federativas gobernadas por el PRI. El modelo también contiene la variable Yuxta, que indica si el municipio tiene un gobierno yuxtapuesto. Algunas interacciones con la variable que indican que no recibieron recursos del FONDEN también se incluyen. Finalmente, $\varepsilon$ es un término de error.

\section{RESULTADOS}

El objetivo de este estudio es discernir si las transferencias gubernamentales de bienes privados inciden sobre el comportamiento electoral. Se estudian tres tipos de municipios: aquellos que tuvieron una $\mathrm{DE}$ y recibieron recursos; los que tuvieron una $\mathrm{DE}, \mathrm{y}$ no recibieron ninguna transferencia, y los que no tuvieron ningún tipo de declaración. La comparación de los tres grupos permite identificar si los votantes premian o castigan al partido gobernante por la intervención realizada cuando un fenómeno natural amenaza o afecta las condiciones de vida de la población.

Se estiman cinco distintas especificaciones con base en el modelo (1) $)^{8}$. En la tabla 6 se presentan los resultados utilizando como variable dependiente la proporción de votos que

7. Una vez que se declara una emergencia, el gobernante puede solicitar tantos recursos como necesite para satisfacer las necesidades de la población durante una DE, hasta que esta sea declarada terminada. Mientras la declaración permanece vigente, todas las peticiones son autorizadas e implican la entrega de recursos.

8. En todas las regresiones se incluyen errores estándar robustos, utilizando la técnica Ericker-Huber-White para evitar posibles problemas de heterocedasticidad. Es destacable que la 
el partido que gobernaba el municipio obtuvo en las elecciones municipales. Los resultados de la tabla 7 se obtienen utilizando como variable dependiente la proporción de votos en las elecciones municipales que obtuvo el partido que gobernaba la entidad federativa.

TABLa 6.

Partido Gobernante en el Municipio

\begin{tabular}{|c|c|c|c|c|c|}
\hline & (1) & (2) & (3) & (4) & (5) \\
\hline \multirow{2}{*}{$\begin{array}{l}\text { Municipio no recibió } \\
\text { transferencias del } \\
\text { FONDEN }^{+}\end{array}$} & $-0,0277^{* *}$ & $-0,0492^{* * *}$ & $-0,0033$ & $-0,0265^{*}$ & $-0,0031$ \\
\hline & {$[0,014]$} & {$[0,013]$} & {$[0,015]$} & {$[0,014]$} & {$[0,016]$} \\
\hline \multirow{2}{*}{$\begin{array}{l}\text { Municipio no tuvo ninguna } \\
\text { declaración }^{+}\end{array}$} & & $0,0874^{* * *}$ & $0,0883^{* * *}$ & $0,0849^{* * *}$ & $0,0838^{* * *}$ \\
\hline & & {$[0,011]$} & {$[0,011]$} & {$[0,011]$} & {$[0,011]$} \\
\hline \multirow{2}{*}{$\begin{array}{l}\text { Porcentaje de emergencias } \\
\text { que recibe FONDEN }\end{array}$} & $-0,0469^{* *}$ & $-0,0620^{* * *}$ & $-0,0353^{*}$ & $-0,0768^{* * *}$ & $-0,0647^{* * *}$ \\
\hline & {$[0,021]$} & {$[0,021]$} & {$[0,021]$} & {$[0,021]$} & {$[0,021]$} \\
\hline \multirow{2}{*}{$\begin{array}{l}\text { Numero de autorizaciones } \\
\text { de recursos }\end{array}$} & 0,0006 & $0,0011^{* *}$ & 0,0009 & 0,0007 & 0,0004 \\
\hline & {$[0,001]$} & {$[0,001]$} & {$[0,001]$} & {$[0,001]$} & {$[0,001]$} \\
\hline \multirow{2}{*}{$\begin{array}{l}\text { Transferencias FONDEN } \\
\text { per cápita }\end{array}$} & $0,0182^{*}$ & 0,0089 & $0,0174^{*}$ & $0,0164^{*}$ & $0,0166^{*}$ \\
\hline & {$[0,009]$} & {$[0,009]$} & {$[0,009]$} & {$[0,009]$} & {$[0,009]$} \\
\hline \multirow{2}{*}{ Gobierno yuxtapuesto } & $-0,0541^{* * *}$ & $-0,0703^{* * *}$ & $-0,0832^{* * *}$ & $-0,0737^{* * *}$ & $-0,0712^{* * *}$ \\
\hline & {$[0,008]$} & {$[0,006]$} & {$[0,006]$} & {$[0,006]$} & {$[0,006]$} \\
\hline \multirow{2}{*}{ PAN gobierna municipio $^{++}$} & $-0,0127$ & $-0,0257^{* * *}$ & $0,0210^{*}$ & & $0,0216^{*}$ \\
\hline & {$[0,008]$} & {$[0,006]$} & {$[0,011]$} & & {$[0,011]$} \\
\hline \multirow{2}{*}{ PRD gobierna municipio $^{++}$} & $-0,0578^{* * *}$ & $-0,0353^{* * *}$ & $-0,0585^{* * *}$ & & $-0,0626^{* * *}$ \\
\hline & {$[0,012]$} & {$[0,010]$} & {$[0,017]$} & & {$[0,016]$} \\
\hline \multirow{2}{*}{ PAN gobierna estado ${ }^{+++}$} & $-0,0320^{* * *}$ & $-0,1042^{* * *}$ & & $-0,0142$ & $-0,0129$ \\
\hline & {$[0,009]$} & {$[0,007]$} & & {$[0,012]$} & {$[0,012]$} \\
\hline \multirow{2}{*}{ PRD gobierna estado ${ }^{+++}$} & $-0,0391^{* * *}$ & $-0,0432^{* * *}$ & & $-0,0400^{* * *}$ & $-0,0227$ \\
\hline & {$[0,011]$} & {$[0,008]$} & & {$[0,014]$} & {$[0,015]$} \\
\hline \multirow{2}{*}{$\begin{array}{l}\text { PAN gobierna municipio * } \\
\text { No FONDEN }\end{array}$} & & & $-0,0780^{* * *}$ & & $-0,0641^{* * *}$ \\
\hline & & & {$[0,014]$} & & {$[0,014]$} \\
\hline \multirow{2}{*}{$\begin{array}{l}\text { PRD gobierna municipio * } \\
\text { No FONDEN }\end{array}$} & & & 0,0205 & & $0,0351^{*}$ \\
\hline & & & {$[0,020]$} & & {$[0,020]$} \\
\hline \multirow{2}{*}{$\begin{array}{l}\text { PAN gobierna estado } * \text { No } \\
\text { FONDEN }\end{array}$} & & & & $-0,1415^{* * *}$ & $-0,1373^{* * *}$ \\
\hline & & & & {$[0,014]$} & {$[0,014]$} \\
\hline
\end{tabular}

significancia de los resultados no cambia, por lo que se puede sostener que este problema no está presente en el modelo. 


\begin{tabular}{|c|c|c|c|c|c|}
\hline & (1) & (2) & (3) & (4) & (5) \\
\hline \multirow{2}{*}{$\begin{array}{l}\text { PRD gobierna estado } * \text { No } \\
\text { FONDEN }\end{array}$} & & & & $-0,0149$ & $-0,0327^{*}$ \\
\hline & & & & {$[0,016]$} & {$[0,017]$} \\
\hline \multirow{2}{*}{ Constante } & $0,4996^{* * *}$ & $0,5706^{* * *}$ & $0,6423^{* * *}$ & $0,4606^{* * *}$ & $0,4295^{* * *}$ \\
\hline & {$[0,112]$} & {$[0,095]$} & {$[0,093]$} & {$[0,095]$} & {$[0,094]$} \\
\hline Observaciones & 2.256 & 4.172 & 4.172 & 4.172 & 4.172 \\
\hline R-squared & 0,116 & 0,171 & 0,142 & 0,181 & 0,191 \\
\hline
\end{tabular}

Errores estándar entre corchetes. ${ }^{* * *} \mathrm{p}<0,01,{ }^{* *} \mathrm{p}<0,05,{ }^{*} \mathrm{p}<0,1$.

Todas las regresiones incluyen controles por variables socioeconómicas, resultados se reportan en Anexo 1. La información acerca de las transferencias per cápita se encuentra en cientos de pesos, a precios constantes de la segunda quincena de diciembre del 2010.

+ El grupo de comparación está compuesto por los municipios que recibieron las transferencias.

++ El grupo de comparación está compuesto por los municipios gobernados por el PRI.

+++ El grupo de comparación está compuesto por las Entidades Federativas gobernadas por el PRI.

Fuente: elaboración propia.

TABLA 7.

Partido Gobernante en la Entidad Federativa

(2)

(3)

(4)

(5)

\begin{tabular}{|c|c|c|c|c|c|}
\hline \multirow{2}{*}{$\begin{array}{l}\text { Municipio no recibió } \\
\text { transferencias del FONDEN }\end{array}$} & $-0,0089$ & $-0,0181$ & $0,0368^{* *}$ & 0,0012 & 0,0202 \\
\hline & {$[0,013]$} & {$[0,013]$} & {$[0,016]$} & {$[0,014]$} & {$[0,015]$} \\
\hline \multirow{2}{*}{$\begin{array}{l}\text { Municipio no tuvo ninguna } \\
\text { declaración }{ }^{+}\end{array}$} & & 0,0061 & 0,0180 & 0,0046 & 0,0049 \\
\hline & & {$[0,011]$} & {$[0,012]$} & {$[0,011]$} & {$[0,011]$} \\
\hline \multirow{2}{*}{$\begin{array}{l}\text { Porcentaje de emergencias } \\
\text { que recibe FONDEN }\end{array}$} & $-0,0303$ & $-0,0541^{* * *}$ & $-0,0082$ & $-0,0625^{* * *}$ & $-0,0608^{* * *}$ \\
\hline & {$[0,021]$} & {$[0,020]$} & {$[0,022]$} & {$[0,021]$} & {$[0,021]$} \\
\hline \multirow{2}{*}{$\begin{array}{l}\text { Numero de autorizaciones } \\
\text { de recursos }\end{array}$} & $-0,0023^{* * *}$ & $-0,0024^{* * *}$ & $-0,0021^{* * *}$ & $-0,0023^{* * *}$ & $-0,0026^{* * *}$ \\
\hline & {$[0,001]$} & {$[0,001]$} & {$[0,001]$} & {$[0,001]$} & {$[0,001]$} \\
\hline \multirow{2}{*}{$\begin{array}{l}\text { Transferencias FONDEN } \\
\text { per cápita }\end{array}$} & $0,0225^{* *}$ & $0,0226^{* *}$ & $0,0346^{* * *}$ & $0,0210^{*}$ & $0,0251^{* *}$ \\
\hline & {$[0,011]$} & {$[0,010]$} & {$[0,012]$} & {$[0,011]$} & {$[0,011]$} \\
\hline \multirow{2}{*}{ Gobierno yuxtapuesto } & $-0,0850^{* * *}$ & $-0,0643^{* * *}$ & $-0,1005^{* * *}$ & $-0,0587^{* * *}$ & $-0,0646^{* * *}$ \\
\hline & {$[0,008]$} & {$[0,006]$} & {$[0,007]$} & {$[0,006]$} & {$[0,006]$} \\
\hline \multirow{2}{*}{ PAN gobierna municipio $^{++}$} & $0,0581^{* * *}$ & $0,0311^{* * *}$ & $0,0678^{* * *}$ & & $0,0609^{* * *}$ \\
\hline & {$[0,008]$} & {$[0,006]$} & {$[0,011]$} & & {$[0,011]$} \\
\hline \multirow{2}{*}{ PRD gobierna municipio ${ }^{++}$} & $0,0280^{* *}$ & $-0,0097$ & 0,0245 & & 0,0241 \\
\hline & {$[0,011]$} & {$[0,009]$} & {$[0,017]$} & & {$[0,016]$} \\
\hline \multirow{2}{*}{ PAN gobierna estado ${ }^{+++}$} & $-0,1002^{* * *}$ & $-0,1337^{* * *}$ & & $-0,1051^{* * *}$ & $-0,1061^{* * *}$ \\
\hline & {$[0,010]$} & {$[0,007]$} & & {$[0,012]$} & {$[0,012]$} \\
\hline
\end{tabular}




\begin{tabular}{|c|c|c|c|c|c|}
\hline & (1) & (2) & (3) & (4) & (5) \\
\hline \multirow{2}{*}{ PRD gobierna estado ${ }^{+++}$} & $-0,1233^{* * *}$ & $-0,1894^{* * *}$ & & $-0,1086^{* * *}$ & $-0,0983^{* * *}$ \\
\hline & {$[0,011]$} & {$[0,008]$} & & {$[0,015]$} & {$[0,016]$} \\
\hline \multirow{2}{*}{$\begin{array}{l}\text { PAN gobierna municipio * } \\
\text { No FONDEN }\end{array}$} & & & $-0,0429^{* * *}$ & & $-0,0396^{* * *}$ \\
\hline & & & {$[0,014]$} & & {$[0,014]$} \\
\hline \multirow{2}{*}{$\begin{array}{l}\text { PRD gobierna municipio * } \\
\text { No FONDEN }\end{array}$} & & & $-0,0900^{* * *}$ & & $-0,0452^{* *}$ \\
\hline & & & {$[0,021]$} & & {$[0,019]$} \\
\hline \multirow{2}{*}{$\begin{array}{l}\text { PAN gobierna estado }{ }^{*} \text { No } \\
\text { FONDEN }\end{array}$} & & & & $-0,0373^{* *}$ & $-0,0384^{* *}$ \\
\hline & & & & {$[0,015]$} & {$[0,015]$} \\
\hline \multirow{2}{*}{$\begin{array}{l}\text { PRD gobierna estado } * \text { No } \\
\text { FONDEN }\end{array}$} & & & & $-0,1094^{* * *}$ & $-0,1119^{* * *}$ \\
\hline & & & & {$[0,017]$} & {$[0,018]$} \\
\hline \multirow{2}{*}{ Constante } & $0,6798^{* * *}$ & $0,6254^{* * *}$ & $0,8449^{* * *}$ & $0,6375^{* * *}$ & $0,6226^{* * *}$ \\
\hline & {$[0,108]$} & {$[0,093]$} & {$[0,100]$} & {$[0,094]$} & {$[0,094]$} \\
\hline Observaciones & 2.256 & 4.172 & 4.172 & 4.172 & 4.172 \\
\hline R-squared & 0,185 & 0,226 & 0,122 & 0,228 & 0,234 \\
\hline
\end{tabular}

Errores estándar entre corchetes. ${ }^{* * *} \mathrm{p}<0,01,{ }^{* *} \mathrm{p}<0,05,{ }^{*} \mathrm{p}<0,1$.

Todas las regresiones incluyen controles por variables socioeconómicas, resultados se reportan en anexo 1. La información acerca de las transferencias per cápita se encuentra en cientos de pesos, a precios constantes de la segunda quincena de diciembre del 2010.

+ El grupo de comparación está compuesto por los municipios que recibieron las transferencias.

++ El grupo de comparación está compuesto por los municipios gobernados por el PRI.

+++ El grupo de comparación está compuesto por las entidades federativas gobernadas por el PRI.

Fuente: elaboración propia.

\section{Efecto electoral de las transferencias del FONDEN durante las declaraciones de emergencia}

a. Transferencias de bienes privados

La primera fila de la tabla 6 presenta el efecto de no recibir recursos del FONDEN después de que una emergencia fuera declarada. En la primera especificación se observa que quienes no recibieron recursos del FONDEN tras la DE votan en promedio 2,8 puntos porcentuales menos por el partido en el poder que quienes sí recibieron apoyo tras la emergencia. No obstante, al incluir las interacciones de las transferencias con las variables políticas, esta variable pierde significancia estadística. Esto sugiere que donde existe una $\mathrm{DE}$, los votantes se comportan igual, independientemente de si recibieron o no recursos. Tener una $\mathrm{DE}$ y recibir bienes privados no garantiza que el partido gobernante obtendrá votos adicionales. Sin embargo, el mero hecho de tener una DE es suficiente para que el electorado penalice en las urnas al gobernante. En los municipios donde no tuvieron ninguna $\mathrm{DE}$ en el trienio, la votación es entre 8,4 y 8,8 
puntos porcentuales superior que en los municipios donde hubo alguna DE. Esto implica que el tener una DE afecta negativamente a la votación del gobernante municipal, independientemente de los daños que haya.

En contraste, en lo que respecta al partido gobernante en el estado, todos los municipios se comportan de la misma manera, independiente de si tuvieron o no una declaración de emergencia, o de si recibieron o no recursos del FONDEN (tabla 7). Estos resultados implican que los votantes tienen un voto diferenciado entre los niveles estatales y municipales, lo que sugiere que los votantes están más informados y conscientes de su voto de lo que usualmente se asume en la TVR. Los votantes hacen responsable al gobierno municipal por el nivel de vulnerabilidad ante los fenómenos naturales, debido a que es el responsable de diseñar e implementar medidas de mitigación de riesgos. Por otro lado, premian al gobierno estatal por las transferencias recibidas, muy probablemente debido a su involucramiento en el proceso para obtener los recursos del FONDEN y repartirlos.

De lo anterior se puede interpretar que la disminución en el nivel de bienestar de la población, a causa de la ocurrencia de la DE, se traduce en una reducción del apoyo al gobernante. La ocurrencia de una DE es interpretada por el electorado como una señal negativa de la capacidad del gobernante para prevenir y proteger a la población ante la ocurrencia de un fenómeno natural. Aunado a esto, se observa que tener una DE no solo afecta negativamente la votación del gobernante municipal, sino también su dimensión. En los municipios que hubo múltiples DE durante el trienio, la proporción de veces que un municipio recibió recursos del FONDEN tiene un efecto negativo sobre la votación del gobernante. El coeficiente sugiere que cuando el $100 \%$ por ciento de las DE en un trienio reciben recursos del FONDEN, el voto del gobernante municipal disminuye, entre 3,6 y 7,7 puntos porcentuales. El efecto negativo del número de transferencias del FONDEN sobre el voto puede estar relacionado con las afectaciones a la población. Cuando un municipio tiene múltiples declaratorias y, en la mayoría de ellas, recibe recursos del FONDEN, implica que la población ha sido constantemente afectada por los fenómenos naturales. Dado que el mayor número de transferencias está relacionado con las necesidades locales. En estos casos, recibir transferencias es una señal de la amplitud y profundidad de los daños.

Por otra parte, en contraste con la literatura, se observa que el monto de recursos transferidos a un municipio no tiene ningún efecto sobre la votación del partido que gobierna el municipio. En todas las especificaciones se observa que el monto per cápita de las transferencias del FONDEN es no significativo estadísticamente. A pesar de que la gente recibe bienes privados, no hay una compensación electoral para el partido gobernante. Esto sugiere que la entrega de bienes privados no garantiza que el partido gobernante obtenga votos adicionales. El valor de las transferencias no aumenta el apoyo al gobernante.

Los electores castigan la ocurrencia de una emergencia, y las transferencias gubernamentales no son relevantes. Los votantes también integran en su proceso de decisión de votos el contexto y la razón por la cual les están entregando eses recursos. Esto refuerza el argumento de que las DE fungen como un mecanismo de 
rendición de cuentas en el que se revela la capacidad de las autoridades para prevenir una emergencia y responder ante ella. Los votantes sí reaccionan a la ocurrencia de una $\mathrm{DE}$ y a los daños que ocasionan, no al hecho de recibir recursos en menor o mayor cuantía.

Si los votantes creen que la declaración se debe a que el desempeño del gobernante los pone en riesgo, entonces será considerada como una mala señal. Los ciudadanos castigarán al gobernante local después de que una emergencia sea declarada, aun si el evento no ocasiona grandes estragos. Estos resultados coinciden con las conclusiones de Ashworth y de Mesquita (2013), quienes argumentan que los votantes penalizan a los gobernantes si consideran que tuvieron mal desempeño.

\section{b. Variables políticas}

Todas las especificaciones incluyen dos vectores de variables políticas referentes a los partidos que gobiernan la entidad federativa y el municipio. En general, se observa que en los municipios con gobierno yuxtapuesto, el partido local tiene entre 5,4 y 8,3 puntos porcentuales menos de apoyo electoral que en los municipios con un gobierno alineado políticamente (tabla 6). Probablemente, esto se deba a que los ciudadanos perciben que existen problemas de coordinación entre ambos niveles de gobierno, y que estos afectan su bienestar. Los votantes no solo responsabilizan al gobierno local por tales problemas. De hecho, el partido del gobernador del estado también obtiene entre 5,9 y 10,5 puntos porcentuales menos de apoyo electoral en los municipios con gobierno yuxtapuesto (tabla 7).

A partir de la tercera especificación se incluyen interacciones de las variables políticas con la variable que indica si los municipios no recibieron recursos del FONDEN durante una emergencia. Primero se incluye la interacción con los partidos que gobiernan el municipio, luego se sustituye por la interacción con los partidos que gobiernan la entidad federativa y, finalmente, se incluyen ambos grupos de interacciones. Las nuevas variables reflejan no solo la diferencia entre los municipios que recibieron y no recibieron recursos durante una declaración de emergencia, sino también cómo este efecto varía entre los municipios gobernados por diferentes partidos.

Los resultados revelan que el efecto de las transferencias depende del partido gobernante. Para facilitar la interpretación de estos efectos, se grafican los resultados. Como se ilustra en el gráfico 1, el porcentaje de votos del PAN en municipios gobernados por este es solo 0,05 puntos porcentuales mayor cuando un fenómeno natural perjudica a los ciudadanos y se transfieren los recursos del FONDEN. En tanto que la proporción de votos del PRI parece aumentar ligeramente y la del PRD disminuir cuando se entregan los recursos del FONDEN. Sin embargo, los cambios no son estadísticamente significativos. Por lo tanto, el PAN es el único partido en el ámbito municipal que obtiene una ligera recompensa electoral cuando se declara una emergencia y la población recibe ayuda del FONDEN, aunque el cambio es marginal. La votación de todos los demás partidos parece no ser afectada cuando se reciben recursos del FONDEN. 


\section{Gráfico i.}

Porcentaje DE VOTO DEL PARTIDO EN EL GOBIERNO MUNICIPAL, DE ACUERDO CON LA RECEPCiÓN DE TRANSFERENCIAS DEL FONDEN EN UNA DE

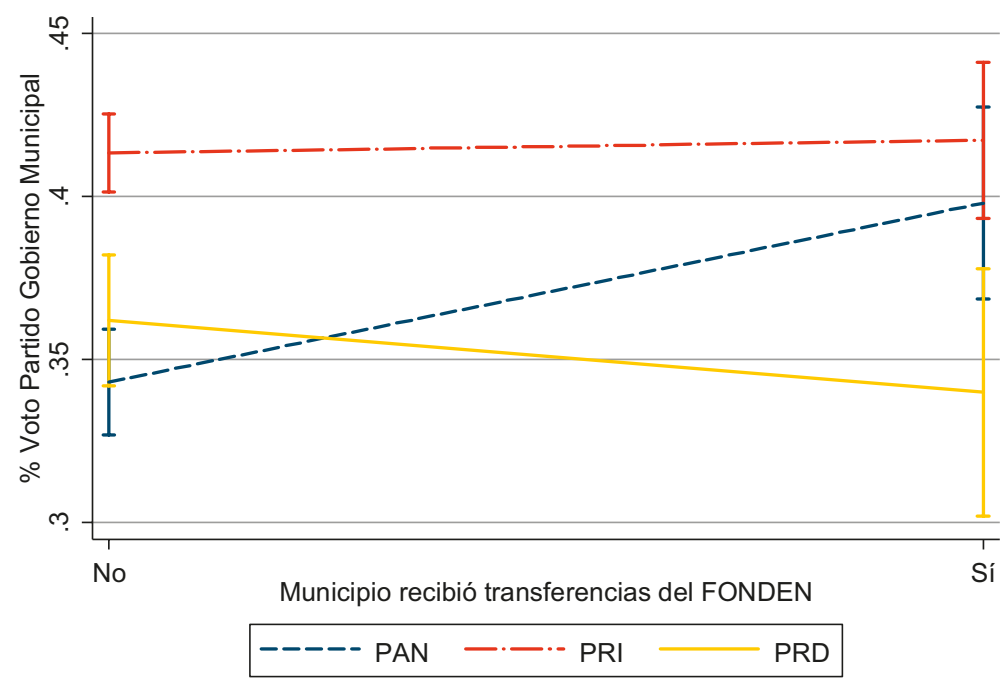

Fuente: elaboración propia con los resultados del quinto modelo de la tabla 6 . Se muestran los intervalos de confianza al $95 \%$.

\section{GrÁFICO 2.}

PorCentaje de VOTO DEL PARTIDO EN El GOBIERNO ESTATAL, DE ACUERDO CON LA RECEPCiÓN DE TRANSFERENCIAS DEL FONDEN EN UNA DE

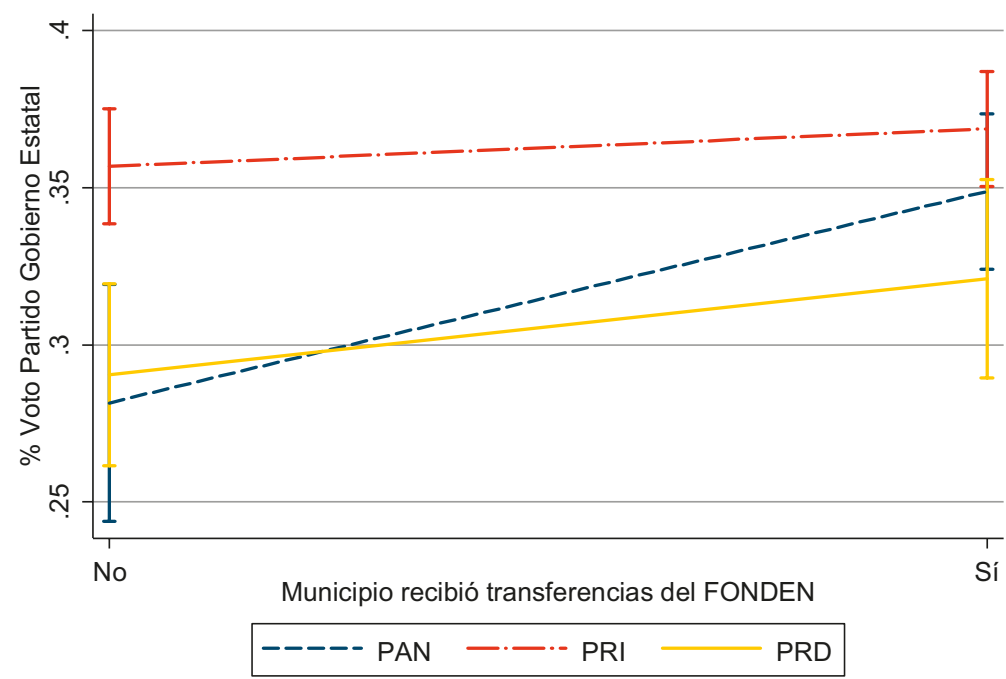

Fuente: elaboración propia con los resultados del quinto modelo de la tabla 7. Se muestran los intervalos de confianza al 95\%. 
Los resultados son diferentes cuando la variable dependiente es el porcentaje de votos que el partido del gobernador del estado obtiene en las elecciones municipales (gráfico 2). En todos los casos, el partido del gobernador del estado recibe más apoyo electoral cuando se entregan los recursos del FONDEN. Sin embargo, estos premios electorales solo son significativos cuando el PAN y el PRD gobiernan, los cuales obtienen 0,17 y 0,06 puntos porcentuales adicional, respectivamente, cuando existe una DE y se proveen bienes privados que cuando no se entregan recursos durante una emergencia. El voto del PRI no tiene un cambio estadísticamente significativo. Los votantes en los municipios ubicados en entidades federativas gobernadas por el PRI parecen ser indiferentes a la recepción de bienes privados.

\section{CONSIDERACIONES FINALES}

De acuerdo con la TVP, los votantes están bien informados y eligen a aquel candidato cuya posición política se asemeje más a la suya y que, por lo tanto, les brinde una mayor utilidad en el futuro. En contraste, la TVR sostiene que la toma de decisiones informadas es un proceso costoso y que las personas emiten su voto utilizando la información disponible o la que pueden obtener con un coste mínimo. En este contexto, los electores tienen la opción de acudir a información privada y a la heurística para decidir el sentido de su voto.

En este trabajo se emplea información inédita del FONDEN para estudiar el comportamiento electoral de los votantes. Una de las ventajas de usar los datos del FONDEN es que tanto las DE como las transferencias son aleatorias. Esto permite corregir por posibles sesgos de endogeneidad atribuibles a la selección de beneficiarios por criterios electorales. Además, en contraste con otras investigaciones, las conclusiones son generalizables pues el análisis incluye personas con diversas características.

La estrategia empírica en esta investigación utiliza tres grupos que surgen después de que una emergencia se declara: (1) municipios con DE que recibieron transferencias privadas; (2) municipios con DE, que no recibieron recursos del FONDEN, y (3) municipios que no tuvieron ningún tipo de declaración. El supuesto de identificación yace en que los fenómenos naturales y, consecuentemente las DE, ocurren de manera aleatoria, por lo que sin estos fenómenos los tres grupos de municipios tendrían un comportamiento electoral similar. Cualquier diferencia en el comportamiento electoral entre los tres grupos es atribuible a la existencia de una $\mathrm{DE}$ o a la recepción de transferencias gubernamentales de bienes privados.

El primer hallazgo de esta investigación es que en los municipios que tuvieron una $\mathrm{DE}$, independientemente de si recibieron o no recursos del FONDEN, se observa un comportamiento electoral distinto al presente en los municipios en los que no hubo ningún tipo de declaratoria. Lo anterior es interpretado como evidencia a favor de la TVR, pues los votantes reaccionan a eventos acontecidos antes de la fecha de las elecciones. La TVP solo se verificaría si los tres grupos estudiados no presentaran diferencias estadísticas, lo cual no es el caso. 
El segundo hallazgo de esta investigación es que las acciones tomadas antes, durante y después de una DE son importantes. Esto no implica que actúen de manera irracional, ya que el castigo no se debe a la ocurrencia del fenómeno natural per se. El apoyo electoral del partido en el poder disminuye cuando ocurre una emergencia, posiblemente por la falta de medidas de prevención o por acciones inapropiadas tras la ocurrencia del fenómeno. Una DE indica a los votantes que estuvieron en una situación de riesgo, atribuible a faltas de medidas de prevención del partido gobernante, lo cual es suficiente para que lo castiguen. Aun si las consecuencias del fenómeno natural no son de tal magnitud que requieran la intervención del FONDEN, los ciudadanos pueden sentir que lo realizado por el gobierno local no fue suficiente o adecuado, y será una mala señal de su desempeño.

Si la disminución del apoyo electoral se debiera al mero hecho de la ocurrencia de una emergencia, no debería haber un comportamiento electoral distinto entre aquellos que reciben bienes privados y aquellos que no. De hecho, de haber una diferencia, se esperaría que la penalización fuera menor entre los electores que recibieron bienes privados, pues la transferencia debería compensar, al menos en parte, el malestar ocasionado por el fenómeno natural. Sin embargo, este no es el caso. El voto de castigo es aún mayor cuando la magnitud del evento es tal que amerita la transferencia de recursos gubernamentales para salvaguardar la salud y el bienestar de la población. Esto sugiere que la forma en cómo los gobernantes reaccionan tras una DE funciona como un insumo en la rendición de cuentas, y que los ciudadanos utilizan su voto para sancionar al partido gobernante por las emergencias mal atendidas.

Esta interpretación se ve reforzada con el tercer hallazgo de este análisis. Cuanto mayor es la proporción de declaraciones que ameriten transferencias del FONDEN, mayor es el voto de castigo. Esto puede estar relacionado con la ocurrencia de daños continuos a la población. La disminución del bienestar de los ciudadanos debido a una exposición constante a fenómenos naturales puede traducirse en una disminución del apoyo electoral al partido que gobierna el municipio.

Además, como cuarto punto que resaltar en esta investigación, sobresale que la evidencia sugiere que los ciudadanos emiten un voto diferenciado por nivel de gobierno. No existe evidencia de que los electores de municipios afectados por DE voten por el gobernante estatal de forma distinta a los no afectados, tal como sí se sucede al referirse al gobernante municipal. Esto sugiere la existencia de votantes informados, que penalizan al gobierno municipal por la existencia de una emergencia.

De manera consistente con la interpretación de los resultados anteriores, se observa que el valor per cápita de los bienes transferidos no incide sobre la votación del partido gobernante en el municipio, que es el responsable de disminuir la vulnerabilidad a los fenómenos naturales; pero sí aumenta la votación del partido del gobernante en el estado, que es el responsable de conseguir los recursos del FONDEN. Esto sugiere que los votantes diferencian las acciones y responsabilidades de cada nivel de gobierno. Los votantes saben que cada nivel de gobierno tiene diferentes responsabilidades durante una emergencia. 
Este estudio también encontró que las variables políticas pueden atenuar o aumentar el voto de castigo. El apoyo electoral que cada uno de los tres principales partidos recibió es diferente entre los municipios que recibieron y no recibieron transferencias del FONDEN después de una DE. El PRI es el único partido cuya votación no se ve afectada por la entrega de recursos del FONDEN. Los ciudadanos en los municipios gobernados por el PRI parecen no responder a las transferencias de bienes privados. El voto de castigo es independiente de si los municipios reciben o no recursos.

Por otra parte, en los municipios o entidades federativas gobernadas por el PAN que recibieron recursos del FONDEN, el castigo a tal partido está entre 0,05 y 0,17 puntos porcentuales menos, respectivamente. No obstante, esta diferencia por la entrega de bienes privados es tan pequeña que, a pesar de ser estadísticamente significativa, no es suficiente para compensar el voto de castigo. Tener una DE siempre perjudica al partido gobernante, independientemente de sí durante ella se transfieren recursos privados o no.

Los hallazgos de esta investigación sugieren que el votante promedio, si bien es retrospectivo, suele estar más informado de lo que usualmente se sugiere en la literatura. Incluso parece que es insensible a las transferencias gubernamentales cuando el desempeño del gobernante no cumple con las expectativas. Estas conclusiones fueron obtenidas gracias a la utilización de información novedosa, jamás antes explorada, que permite identificar, libre de sesgos políticos, cuál es la influencia de las transferencias gubernamentales sobre el comportamiento del votante promedio, no solo de aquellos en situación de pobreza. Esto sugiere la necesidad de cuestionar la evidencia prevaleciente hasta ahora, y de expandir las fuentes de información y métodos de análisis, a fin de reconfirmar o rechazar la caracterización de los votantes, que hasta ahora impera en la literatura.

\section{Referencias}

Achen, Christopher H. y Larry M. Bartels. 2004. «Musical Chairs. Pocketbook Voting and the Limits of Democratic Accountability», en Annual Meeting of the American Political Science Association. Disponible en: https://bit.ly/2tOfmgb.

Achen, Christopher H. y Larry M. Bartels. 2012. Blind Retrospection: Why Shark Attacks Are Bad For Democracy. Working Paper 5-2013. Center for the Study of Democratic Institutions. Nashville: Vanderbilt University. Disponible en: https:// bit.ly/2MqjKte.

Ashworth, Scott y Ethan Bueno de Mesquita. 2013. Disasters and Incumbent Electoral Fortunes: No Implications for Democratic Competence. Chicago: Harris School of Public Policy Studies, University of Chicago. Disponible en: https://bit.ly/2ItkP1d.

Baez, Javier E., Adriana Camacho, Emily Conover y Román A. Zárate. 2012. Conditional Cash Transfers, Political Participation, and Voting Behavior. IZA Discussion Paper No. 6870. Bonn: IZA. Disponible en: http://ftp.iza.org/dp6870.pdf. 
Bonfiglioli, Alessandra y Gino Gancia. 2013. «Uncertainty, Electoral Incentives and Political Myopia», The Economic Journal, 123: 373-400. Disponible en: https:// doi.org/10.1111/ecoj.12029.

Brender, Adi y Allan Drazen. 2005. «Political Budget Cycles in New versus Established Democracies», Journal of Monetary Economics, 52 (7): 1271-1295. Disponible en: https://doi.org/10.1016/j.jmoneco.2005.04.004.

CENAPRED. 2013. Base de datos sobre Declaratorias de Emergencia, Desastre y Contingencia climatológica. Disponible en: https://bit.ly/2Kn0mN5.

Chen, Jowei y Andrew Healy. 2015. How Do Voters Retrospectively Evaluate Wasteful Government Spending? Evidence from Individual-Level Disaster Relief. Disponible en: https://bit.ly/2tOjpsT.

CIDAC. 2013. Resultados electorales 1985-2012. Disponible en: http://elecciones. cidac.org.

Cole, Shawn, Andrew Healy y Eric Werker. 2012. «Do Voters Demand Responsive Governments? Evidence from Indian Disaster Relief», Journal of Development Economics, 97 (2): 167-181. Disponible en: https://doi.org/10.1016/j.jdeveco.2011.05.005.

CONAPO. 2013. Índices de Marginación. Disponible en: https://bit.ly/1RkFur2.

Cox, Gary W. y M. McCubbins. 1986. «Electoral Politics as a Redistributive Game», Journal of Politics, 48 (1):370-389. Disponible en: https://doi.org/10.2307/2131098.

De la O, Ana. 2013. «Do Conditional Cash Transfers Affect Electoral Behavior? Evidence from a Randomized Experiment in Mexico» American Journal of Political Science, 57 (1): 1-14.

De Mesquita, Ethan Bueno y Amanda Friedenberg. 2006. Optimal Retrospective Voting. Chicago: MIMEO.

Díaz-Cayeros, Alberto, Federico Estévez y Beatriz Magaloni. 2009. «Welfare Benefits, Canvassing, and Campaign Handouts», en Jorge I. Domínguez, Chappell H. Lawson y Alejandro Moreno (eds.), Consilidating Mexico's Democracy. Baltimore: Johns Hopkins University Press.

Downs, Anthony. 1957. "An Economic Theory of Political Action in a Democracy», Journal of Political Economy, 65 (2): 135-150. Disponible en: https://doi. org/10.1086/257897.

Drazen, Allan y Marcela Eslava. 2010. «Electoral Manipulation Via Voter-Friendly Spending: Theory and Evidence». Journal of Development Economics, 92 (1): 39-52. Disponible en: https://doi.org/10.1016/j.jdeveco.2009.01.001.

Elinder, Mikael, Henrik Jordahl y Panu Poutvaara. 2015. Promises, Policies and Pocketbook Voting», European Economic Review 75: 177-194. Disponible en: https:// doi.org/10.1016/j.euroecorev.2015.01.010.

Fiorina, Morris P. 1981. Retrospective Voting in American National Elections. New Haven, CT: Yale University Press.

Healy, Andrew y Gabriel S. Lenz. 2014. «Substituting the End for the Whole: Why Voters Respond Primarily to the Election-Year Economy», American Journal of Political Science 58 (1): 31-47. Disponible en: https://doi.org/10.1111/ajps.12053. 
Hellwig, Timothy. 2010. «Elections and the Economy», en Lawrence LeDuc, Richard G. Niemi y Pippa Norris (eds.), Comparing Democracies: Elections and Voting in the 21st Century. Thousand Oaks, California: SAGE. Disponible en: https://doi. org/10.4135/9781446288740.n9.

INEGI. 2013a. Índice de Precios. Disponible en: https://bit.ly/2tIcNvJ.

INEGI. 2013b. Sistema Municipal de Bases de Datos, SIMBAD. Disponible en: https:// bit.ly/2ft27IA.

Labonne, Julien. 2013. «The Local Electoral Impacts of Conditional Cash Transfers. Evidence from a Field Experiment», Journal of Development Economics, 104: 73-88. Disponible en: https://doi.org/10.1016/j.jdeveco.2013.04.006.

Ladd, Jonathan McDonald. 2010. «Is Presidential Approval Myopic?». Disponibel en: https://bit.ly/2yJRTCv.

Lenz, Gabriel S. 2011. "Understanding and Curing Myopic Voting.» Massachusetts Institute of Technology: MIMEO.

Lewis-Beck, Michael. S. y Mary Stegmaier. 2007. «Economic Models of Voting», en Russell Dalton y Hans-Dieter Klingemann (eds.), The Oxford Handbook of Political Behavior. Oxford: Oxford University Press.

Lindbeck, Assar, y Jörgen Weibull. 1987. «Balanced Budget Redistribution and the Outcome of Political Competition", Public Choice, 52: 273-297. Disponible en: https://doi.org/10.1007/BF00116710.

Manacorda, Marco, Edward M., y Andrea Vigorito. 2011. "Government Transfers and Political Support», American Economic Journal: Applied Economics, 3 (3): 1-28. Disponible en: https://doi.org/10.1257/app.3.3.1.

Nielsen, Sigge Winther y Martin Vinæs Larsen. 2014. «Party brands and voting», Electoral Studies, 33: 153-165. Disponible en: https://doi.org/10.1016/j. electstud.2013.08.001.

Persson, Torsten y Guido Tabellini. 2000. Political Economics: Explaining Economic Policy. Cambridge, Massachusetts: MIT Press.

Pop-Eleches, Cristian, y Grigore Pop-Eleches. 2009. Government Spending and Pocketbook Voting: Quasi-Experimental Evidence from Romania. Columbia University Working Paper. New York: Columbia University. Disponible en: https://bit. ly/2tzLq7U.

Rodriguez-Chamussy, Lourdes. 2009. Local Electoral Rewards from Centralized Social Programs: Are Mayors Successful at Credit Claiming? Berkeley: University of California at Berkeley.

Rogoff, Kenneth S. 1990. «Equilibrium Political Budget Cycles», The American Economic Review, 80 (1): 21-36.

SEGOB. 2010. «Acuerdo por el que se emiten las Reglas de Generales del Fondo de Desastres Naturales», Diario Oficial de la Federación, 3-12-2010. Disponible en: https://bit.ly/2N0LsOx.

SEGOB. 2012. «Acuerdo que establece los Lineamientos del Fondo para la Atención de Emergencias FONDEN», Diario Oficial de la Federación. 3-7-2012. 
Shia, Min y Jakob Svensson. 2006. «Political Budget Cycles: Do They Differ Across Countries and Why?», Journal of Public Economics, 90 (8-9): 1367-1389. Disponible en: https://doi.org/10.1016/j.jpubeco.2005.09.009.

TEPJF. 2013. Calendario electoral. Disponible en: https://bit.ly/2yOQNVY.

Zucco, Cesar Jr. 2013. "When Payouts Pay Off: Conditional Cash Transfers and Voting Behavior in Brazil 2002-10», American Journal of Political Science, 57 (4): 810-822. Disponible en: https://doi.org/10.1111/ajps.12026.

\section{ANEXO I}

TABla 8.

Partido gobernante EN El MUNicipio (VARIAbles SOCIODEMOGRÁficas)

\begin{tabular}{|c|c|c|c|c|c|}
\hline & (1) & (2) & (3) & (4) & (5) \\
\hline \multirow{2}{*}{ Población } & $0,0000^{* * *}$ & $0,0000^{* * *}$ & $0,0000^{* * *}$ & $0,0000^{* * *}$ & $0,0000^{* * *}$ \\
\hline & {$[0,000]$} & {$[0,000]$} & {$[0,000]$} & {$[0,000]$} & {$[0,000]$} \\
\hline \multirow{2}{*}{$\begin{array}{l}\text { Proporción de población con } \\
\text { analfabetismo }\end{array}$} & $-0,0069$ & 0,0283 & 0,1077 & 0,0204 & 0,0413 \\
\hline & {$[0,106]$} & {$[0,079]$} & {$[0,078]$} & {$[0,078]$} & {$[0,079]$} \\
\hline \multirow{2}{*}{$\begin{array}{l}\text { Proporción de población con } \\
\text { primaria incompleta }\end{array}$} & 0,0444 & $-0,0650$ & $-0,0965^{*}$ & $-0,0502$ & $-0,0583$ \\
\hline & {$[0,072]$} & {$[0,054]$} & {$[0,056]$} & {$[0,053]$} & {$[0,053]$} \\
\hline \multirow{2}{*}{$\begin{array}{l}\text { Proporción de hogares sin } \\
\text { drenaje }\end{array}$} & $0,2143^{* * *}$ & $0,2139^{* * *}$ & $0,1564^{* * *}$ & $0,1806^{* * *}$ & $0,1840^{* * *}$ \\
\hline & {$[0,037]$} & {$[0,034]$} & {$[0,034]$} & {$[0,035]$} & {$[0,034]$} \\
\hline \multirow{2}{*}{$\begin{array}{l}\text { Proporción de hogares sin } \\
\text { energía eléctrica }\end{array}$} & 0,0438 & 0,0398 & 0,0420 & 0,0803 & 0,0713 \\
\hline & {$[0,081]$} & {$[0,057]$} & {$[0,057]$} & {$[0,057]$} & {$[0,057]$} \\
\hline \multirow{2}{*}{$\begin{array}{l}\text { Proporción de hogares sin } \\
\text { agua potable }\end{array}$} & 0,0025 & $-0,0160$ & 0,0159 & $-0,0043$ & $-0,0060$ \\
\hline & {$[0,024]$} & {$[0,019]$} & {$[0,020]$} & {$[0,019]$} & {$[0,019]$} \\
\hline \multirow{2}{*}{$\begin{array}{l}\text { Proporción de hogares con } \\
\text { hacinamiento }\end{array}$} & 0,0196 & 0,0449 & 0,0069 & 0,0208 & 0,0087 \\
\hline & {$[0,049]$} & {$[0,038]$} & {$[0,037]$} & {$[0,037]$} & {$[0,037]$} \\
\hline \multirow{2}{*}{$\begin{array}{l}\text { Proporción de hogares con } \\
\text { piso de tierra }\end{array}$} & $-0,0487$ & $-0,0747^{* *}$ & $-0,0386$ & $-0,0839^{* * *}$ & $-0,0834^{* * *}$ \\
\hline & {$[0,040]$} & {$[0,031]$} & {$[0,031]$} & {$[0,031]$} & {$[0,031]$} \\
\hline \multirow{2}{*}{ Latitud } & $0,0000^{* * *}$ & $0,0000^{* * *}$ & $0,0000^{* * *}$ & $0,0000^{* * *}$ & $0,0000^{* *}$ \\
\hline & {$[0,000]$} & {$[0,000]$} & {$[0,000]$} & {$[0,000]$} & {$[0,000]$} \\
\hline \multirow{2}{*}{ Longitud } & $-0,0000^{* *}$ & $-0,0000^{* *}$ & $-0,0000^{* * *}$ & $-0,0000$ & $-0,0000$ \\
\hline & {$[0,000]$} & {$[0,000]$} & {$[0,000]$} & {$[0,000]$} & {$[0,000]$} \\
\hline \multirow{2}{*}{ Altitud } & $-0,0000^{* *}$ & 0,0000 & $0,0000^{*}$ & 0,0000 & $0,0000^{*}$ \\
\hline & {$[0,000]$} & {$[0,000]$} & {$[0,000]$} & {$[0,000]$} & {$[0,000]$} \\
\hline
\end{tabular}

Errores estándar entre corchetes. ${ }^{* * *} \mathrm{p}<0,01,{ }^{* *} \mathrm{p}<0,05,{ }^{*} \mathrm{p}<0,1$.

Variables socioeconómicas omitidas en los resultados de la Tabla 6.

Fuente: elaboración propia. 
TABla 9.

Partido Gobernante en la Entidad Federativa (variables Sociodemográficas)

\begin{tabular}{|c|c|c|c|c|c|}
\hline & (1) & (2) & (3) & (4) & (5) \\
\hline \multirow{2}{*}{ Población } & 0,0000 & $0,0000^{* *}$ & 0,0000 & $0,0000^{* *}$ & $0,0000^{* *}$ \\
\hline & {$[0,000]$} & {$[0,000]$} & {$[0,000]$} & {$[0,000]$} & {$[0,000]$} \\
\hline \multirow{2}{*}{$\begin{array}{l}\text { Proporción de población con } \\
\text { analfabetismo }\end{array}$} & $-0,1208$ & $-0,1659^{* *}$ & 0,0002 & $-0,2084^{* * *}$ & $-0,1922^{* *}$ \\
\hline & {$[0,093]$} & {$[0,076]$} & {$[0,083]$} & {$[0,075]$} & {$[0,075]$} \\
\hline \multirow{2}{*}{$\begin{array}{l}\text { Proporción de población con } \\
\text { primaria incompleta }\end{array}$} & $-0,0490$ & $-0,0573$ & $-0,2093^{* * *}$ & $-0,0089$ & $-0,0301$ \\
\hline & {$[0,070]$} & {$[0,056]$} & {$[0,059]$} & {$[0,055]$} & {$[0,055]$} \\
\hline \multirow{2}{*}{$\begin{array}{l}\text { Proporción de hogares sin } \\
\text { drenaje }\end{array}$} & $0,3255^{* * *}$ & $0,4905^{* * *}$ & $0,3726^{* * *}$ & $0,4468^{* * *}$ & $0,4577^{* * *}$ \\
\hline & {$[0,039]$} & {$[0,034]$} & {$[0,036]$} & {$[0,034]$} & {$[0,034]$} \\
\hline \multirow{2}{*}{$\begin{array}{l}\text { Proporción de hogares sin } \\
\text { energía eléctrica }\end{array}$} & $-0,2373^{* * *}$ & $-0,2856^{* * *}$ & $-0,1882^{* * *}$ & $-0,2590^{* * *}$ & $-0,2688^{* * *}$ \\
\hline & {$[0,088]$} & {$[0,068]$} & {$[0,068]$} & {$[0,068]$} & {$[0,068]$} \\
\hline \multirow{2}{*}{$\begin{array}{l}\text { Proporción de hogares sin } \\
\text { agua potable }\end{array}$} & $-0,0100$ & 0,0102 & 0,0364 & 0,0090 & 0,0086 \\
\hline & {$[0,026]$} & {$[0,020]$} & {$[0,022]$} & {$[0,020]$} & {$[0,020]$} \\
\hline \multirow{2}{*}{$\begin{array}{l}\text { Proporción de hogares con } \\
\text { hacinamiento }\end{array}$} & 0,0443 & $-0,0308$ & $-0,1264^{* * *}$ & $-0,0373$ & $-0,0478$ \\
\hline & {$[0,049]$} & {$[0,039]$} & {$[0,040]$} & {$[0,039]$} & {$[0,039]$} \\
\hline \multirow{2}{*}{$\begin{array}{l}\text { Proporción de hogares con } \\
\text { piso de tierra }\end{array}$} & 0,0099 & $-0,0118$ & 0,0458 & $-0,0171$ & $-0,0106$ \\
\hline & {$[0,042]$} & {$[0,034]$} & {$[0,037]$} & {$[0,034]$} & {$[0,034]$} \\
\hline \multirow{2}{*}{ Latitud } & 0,0000 & 0,0000 & $0,0000^{* * *}$ & 0,0000 & 0,0000 \\
\hline & {$[0,000]$} & {$[0,000]$} & {$[0,000]$} & {$[0,000]$} & {$[0,000]$} \\
\hline \multirow{2}{*}{ Longitud } & $-0,0000^{* *}$ & $-0,0000$ & $-0,0000^{* * *}$ & $-0,0000^{*}$ & $-0,0000$ \\
\hline & {$[0,000]$} & {$[0,000]$} & {$[0,000]$} & {$[0,000]$} & {$[0,000]$} \\
\hline \multirow{2}{*}{ Altitud } & $-0,0000^{* *}$ & $-0,0000$ & 0,0000 & $-0,0000$ & $-0,0000$ \\
\hline & {$[0,000]$} & {$[0,000]$} & {$[0,000]$} & {$[0,000]$} & {$[0,000]$} \\
\hline
\end{tabular}

Errores estándar entre corchetes. ${ }^{* * *} \mathrm{p}<0,01,{ }^{* *} \mathrm{p}<0,05,{ }^{*} \mathrm{p}<0,1$.

Variables socioeconómicas omitidas en los resultados de la tabla 7.

Fuente: elaboración propia.

Presentado para evaluación: 9 de agosto de 2017.

Aceptado para publicación: 28 de mayo de 2018.

\section{BRISNA BELTRÁN}

brisna.beltran@gmail.com

Doctora y maestra en Economía por el Colegio de México, máster en Cooperación Internacional y Desarrollo por la Universidad de Cantabria (España), y licenciada en Relaciones Internacionales y Ciencias Políticas por el Centro de Investigación y Docencia Económicas. Sus líneas de investigación son: economía política, desastres, desarrollo, pobreza y economía de género. 